\title{
Como ensinar filosofia em uma educação maior: uma análise bourdieuana do sistema de ensino
}

\author{
How to teach philosophy in a major education: a bourdieuan analysis of the \\ education system
}

\author{
Matheus Diesel Werberich \\ Graduando na Universidade Federal de Santa Maria, Santa Maria, Rio Grande do Sul, Brasil. \\ matheusdiesel01@gmail.com \\ ORCID: https://orcid.org/0000-0002-9297-9089
}

Recebido em 05 de agosto de 2019

Aprovado em 11 de novembro de 2019

Publicado em 07 de janeiro de 2020

RESUMO: No presente artigo, constata-se o modo como o ensino de filosofia no Brasil, visto como educação maior, é utilizado como ferramenta da inculcação de um arbitrário cultural a partir de uma análise bourdieuana do sistema de ensino. Chegou-se à conclusão que a prioridade conferida ao texto clássico de filosofia no ensino médio é um modo de reprodução das mesmas estruturas sociais que permitem a impossibilidade de ascensão social. Com isso, é proposta uma educação menor, cuja constituição fundamental é a relação entre professor e aluno, capaz de subverter as características da educação maior. Para tanto, foram analisados os textos de Sílvio Gallo (2002; 2006), os quais apontam para a valorização do capital cultural dos alunos, o incentivo à criação autônoma de conceitos e escolha de autoras e autores não canônicos como ferramentas de subversão dos mecanismos da educação maior. Palavras-chave: Ensino de filosofia; Sociologia da educação; Educação maior; Educação menor

\begin{abstract}
In the present paper, we determine, through a bourdieuan analysis of the educational system, the way teaching of philosophy in Brazil, viewed as major education, is used as a tool of inculcation of a cultural arbitrary. We've come to the conclusion that the priority attributed to the classical texts of philosophy is a way of reproduction of the same social structures that allow the impossibility of social ascension. With it, it's proposed a minor education, whose main constituent is the relation between teacher and student, capable of subverting the characteristics of major education. For this purpose, the texts of Silvio Gallo $(2002 ; 2006)$ were analyzed, which point to the valorization of students' cultural capital, the incentive to autonomous creation of concepts and the choice of non-canonical authors as tools of subversion of the mechanisms of major education. Keywords: Teaching of philosophy; Sociology of education; Major education; Minor education.
\end{abstract}




\section{Introdução}

A educação contemporânea pode ser estudada de diversos níveis e perspectivas. Existem aqueles que a estudam através dos processos cognitivos de aprendizagem, outros que a analisam por meio de políticas públicas específicas de cada país e como essas influenciam no processo educativo, ao passo que outros ainda procuram os fundamentos filosóficos da educação, buscando esclarecimentos conceituais sobre o ensinar e o aprender. Entretanto, por mais que sejam distintas todas essas perspectivas, esses estudos sempre operam sob dois pontos de vista: o nível maior das decisões políticas e estruturas sociológicas da educação e o nível menor da relação entre professores e alunos, onde o ensino e a aprendizagem efetivamente acontecem. Naturalmente, há interações entre esses dois níveis que são relevantes para um estudo holístico da educação: podemos estudar o processo educacional como uma estrutura top-down, em que as decisões governamentais e as funções sociológicas das instituições escolares influenciam o modo como se relacionam professor e aluno, assim como também existem interações bottom-up, onde os agentes do cotidiano escolar reagem às políticas governamentais e criam condições de possibilidade para a mudança no processo como um todo.

Os níveis de estudo da educação apontados acima condizem com a distinção que os filósofos Gilles Deleuze e Félix Guatarri (1986) fazem acerca sobre dois diferentes modos de análise da literatura: literatura maior e menor. No seu livro Kafka: toward a minor literature (1986), os autores afirmam que a literatura maior é aquela feita por aqueles grupos sociais que se encontram já consolidados no seu poder político e econômico e, por conta disso, têm o seu valor cultural mais valorizado dentro da sociedade. A própria linguagem dessa forma de literatura já se encontra carregada das marcas sociais dos seus autores: seu vocabulário é rebuscado, as regras gramaticais são estritamente seguidas, e a forma de se expressar é repleta de metáforas e analogias. No caso da literatura alemã, Deleuze e Guatarri apontam para Goethe como sendo o exemplo mais evidente da literatura maior (1986), ao passo que podemos identificar Olavo Bilac como sendo um dos maiores representantes da literatura maior brasileira.

Por outro lado, a literatura menor se caracteriza por oferecer um contraponto à literatura maior. Na medida em que os seus autores se encontram em grupos marginalizados da sociedade, existe uma subversão da língua estabelecida que reflete os traços culturais e sociais desses grupos. A presença de gírias, a desconsideração das regras gramaticais para representar como a língua é falada no cotidiano, e a linguagem simples e direta são formas de se utilizar da língua da literatura maior para representar o lado excluído da sociedade.

A partir dessas considerações sobre a literatura, o filósofo brasileiro Sílvio Gallo (2002) denomina os níveis de análise da educação de educação maior, a que diz respeito às políticas governamentais e às estruturas sociológicas da educação, e educação menor, que se encontra dentro da esfera da educação maior, mas subverte muitos dos seus mecanismos para refletir e mudar a sua própria realidade.

Desse modo, a presente análise do ensino médio e do ensino de filosofia se ordenará da seguinte forma: primeiramente será feita uma exposição da educação maior, partindo principalmente dos estudos do sociólogo Pierre Bourdieu (1982; 1998). Serão 
objetos dessa exposição as finalidades do sistema educativo e da instituição escolar, sendo elas principalmente a manutenção da ordem social e da classificação dos alunos quanto a sua classe social e adequação à disciplina da escola. Com isso, verificar-se-á as consequências desse sistema para o ensino de filosofia. Após isso, será conduzida uma análise do conceito de educação menor, caracterizada por autores como Silvio Gallo (2002; 2006), na qual há uma possibilidade de uma educação consciente das estruturas de reprodução da ordem social, bem como de um ensino filosófico propriamente dito.

\section{A escola e o ensino médio: uma análise a partir de Bourdieu e Passeron}

Considerado por muitos como um dos maiores teóricos da sociologia, Pierre Bourdieu dedicou muito de sua obra ao estudo do sistema de ensino e o seu papel na estrutura social e econômica da sociedade. Desde a sua criação pelo sociólogo francês em 1975, a revista de sociologia Actes de la Recherche en Sciences Sociales (ARSS) publicou cerca de uma centena de artigos de Bourdieu, sendo que uma parte considerável desses se tratou da educação. Nesses artigos, encontram-se três grandes períodos do pensamento desse autor com relação ao sistema de ensino (HEY et. al., 2018): sua primeira fase, característica dos escritos dos anos de 1970, Bourdieu estabeleceu as bases teóricas para a tese que permeará todo o seu pensamento sobre a educação, a saber, que o sistema educacional tem como função principal a reprodução de um arbitrário cultural, o qual foi determinado pela classe dominante para perpetuação da mesma. A sua segunda fase se trata de uma análise empírica desses mecanismos de reprodução social, realizada nas instituições de ensino superior francesas dos anos 1980. Esses estudos visavam mostrar como o capital cultural herdado pelos alunos de suas famílias lhes é determinante para o ingresso no ensino superior. Já na sua terceira fase, Bourdieu constatou que as mesmas estruturas de reprodução social se encontram em um contexto diferente, a saber, o processo de democratização que as escolas francesas passaram pelos anos de 1990 e 2000. Tendo em vista que a primeira fase serve de fundamento para todas as outras, uma vez que nela estão contidas todas as teses centrais de Bourdieu sobre o sistema educativo, a presente análise a terá como objeto central, sendo que principal obra analisada será A Reprodução (1982) de Bourdieu e Jean Claude Passeron.

Inaugurando os estudos de Bourdieu e Passeron sobre a sociologia da educação, o livro A Reprodução, publicado originalmente em 1970, estabelece os fundamentos para uma teoria da violência simbólica e, em decorrência disso, do sistema de ensino. Segundo os autores, o poder de violência simbólica (VS) é definido como o poder de impor significações como legítimas, ao mesmo tempo em que consegue dissimular as relações de força que estão na sua base. Com isso, Bourdieu e Passeron unem de tal modo as relações simbólicas das relações de força que as primeiras intrinsicamente dependentes das segundas, razão pela qual eles afirmam que esse axioma é o "princípio da teoria do conhecimento sociológico" (BOURDIEU; PASSERON, 1982, p. 19). A partir disso, toda ação pedagógica (AP) é uma forma de VS, na medida em que impõe um arbitrário cultural a partir de um poder arbitrário, o qual se encontra fundamentado pelas relações de forças entre os grupos constitutivos da formação social em questão: 
A AP é objetivamente uma violência simbólica, num primeiro sentido, enquanto que as relações de força entre os grupos ou as classes constitutivas de uma formação social estão na base do poder arbitrário que é a condição da instauração de uma relação de comunicação pedagógica, isto é, da imposição e da inculcação de um arbitrário cultural [...] (BOURDIEU; PASSERON, 1982, p. 21).

Desse modo, a ação pedagógica não é exclusiva da escola, mas se encontra em toda e qualquer formação social, tais como a família, a igreja ou determinado partido político, na qual existe um arbitrário cultural dominante que foi selecionado arbitrariamente (ou seja, não foi deduzido de nenhum princípio universal ou interno à natureza das coisas) por um grupo ou classe social dominante. Essa seleção, contudo, ainda é sociologicamente necessária, pois sua inteligibilidade é dependente da estrutura das relações sociais que constituem a formação social e, também, porque exprime os interesses objetivos da classe dominante. Com isso, conclui-se que a ação pedagógica é um meio de reprodução desse arbitrário cultural.

Por ser uma violência simbólica, a ação pedagógica não consegue ter o seu efeito desejado se não dissimular as relações de força simbólicas que estão na sua base, uma vez que ela perderia sua credibilidade caso revelasse a sua verdade objetiva:

Encontrar-se-ia então uma nova forma do paradoxo de Epimênides, o Mentiroso: ou bem você acredita que eu não minto quando lhe digo que a educação é violência e meu ensino não é legítimo, pois você não pode me acreditar; ou então você acredita que eu minto e meu ensino é legítimo, pois você não pode mais acreditar o que eu digo quando digo que ela é violência (BOURDIEU; PASSERON, 1982, p. 26).

Para resolver esse problema, a AP se utiliza da autoridade pedagógica (AuP) para esconder a sua verdade objetiva e seu poder arbitrário, bem como para ganhar legitimidade perante aqueles aos quais é imposto o arbitrário cultural. Desse modo, a AuP garante a legitimidade da AP na medida em que ela mesma é desconhecida na sua verdade objetiva: o seu direito de imposição cultural somente é considerado como legítimo quando se desconhece o poder arbitrário que a estabeleceu. Com isso, torna-se claro o fato de que a AP, bem como a AuP, precisam ser em grande parte desconhecidas para que possam ser exercidas na sua formação social (razão pela qual muitos estudantes do ensino médio, assim como os seus professores, não conseguem uma resposta para a pergunta "afinal, por que preciso aprender, ou ensinar, isso?"). Afirmam Bourdieu e Passeron:

Na medida em que está investida de uma AuP, a AP tende a produzir o desconhecimento da verdade objetiva do arbitrário cultural, pelo fato de que, reconhecida como instância legítima de imposição, ela tende a produzir o reconhecimento do arbitrário cultural que ela inculca como cultura legítima (BOURDIEU; PASSERON, 1982, p. 35). 
A essa inculcação do arbitrário cultural Bourdieu e Passeron (1982) dão o nome de trabalho pedagógico (TP), o qual, segundo os autores, tem como objetivo final a formação de um habitus cultural a partir da interiorização do arbitrário cultural. Essa assimilação da cultura imposta pela AP deve ser mais duradoura no sujeito receptivo que o próprio TP, uma vez que esse sujeito deve continuar a reproduzir esse arbitrário cultural para além dos seus anos de formação. Assim, o trabalho pedagógico é uma das formas mais efetivas da reprodução das condições sociais do arbitrário cultural, já que os seus efeitos se perpetuam muito após a sua aplicação: "[...] o TP tende a reproduzir as condições sociais de produção desse arbitrário cultural [...] pela mediação do hábito como princípio gerador de práticas reprodutoras das estruturas objetivas" (BOURDIEU, PASSERON, 1982, p. 45).

Além disso, o TP ganha outras características quando aplicado dentro do sistema de ensino institucionalizado (SE). Segundo Bourdieu e Passeron, o SE tem as mesmas finalidades e características do TP: ambos têm a função de reprodução e inculcação de um arbitrário cultural, além de deverem as suas características próprias ao mesmo contexto social que eles têm como finalidade perpetuar. Assim, tanto o TP quanto o SE se autorreproduzem na medida em que perpetuam um arbitrário cultural, o qual é a condição de manutenção da ordem social que, por sua vez, legitima e faz existir o TP e o SE. Por conta disso, o SE se utiliza do trabalho pedagógico institucionalizado (chamado pelos autores de "trabalho escolar", ou TE) para criar um habitus tão uniforme e contínuo, tanto dentro dos próprios limites da instituição quanto fora dela. Para garantir a homogeneidade e ortodoxia do TE, o sistema de ensino se responsabiliza pela formação dos seus agentes, no caso os professores, garantindo que eles reproduzam o trabalho escolar em questão e, com isso, que passem esse TE à próxima geração de agentes.

\section{O ensino de filosofia como um possível mecanismo de reprodução social}

Conforme foi salientado na seção anterior, a instituição escolar tem como função macrossociológica a inculcação e perpetuação de um arbitrário cultural, o qual foi escolhido e é constantemente valorizado pela sua utilidade de manutenção da ordem social. Agora, restanos analisar como o ensino de filosofia pode também estar a serviço desse projeto. Para tanto, antes precisamos considerar o que constitui, de modo fundamental, uma aula de filosofia.

Segundo Ronai Pires da Rocha (2013), uma aula de filosofia possui três eixos centrais: (a) o eixo temático, onde se encontra o problema filosófico a ser discutido, bem como a conexão desse com o cotidiano dos alunos; (b) o eixo lógico e instrumental, no qual são destacados os métodos de análise lógica e conceitual dos problemas do primeiro eixo; e (c) o eixo histórico e textual, onde há um contato dos alunos com textos filosóficos que abordam o tema central da aula. Com isso, a aula de filosofia se estrutura em torno de um problema filosófico central, o qual é apresentado aos alunos fazendo referência à sua relevância no seu cotidiano, para depois ser analisado com as ferramentas conceituais e com o texto clássico da história da filosofia.

A partir disso, podemos observar que uma aula de filosofia pode servir às finalidades macrossociológicas do sistema de ensino ao dar prioridade apenas para o terceiro eixo do ensino filosófico. Sem o incentivo à argumentação e à capacidade de reflexão que os eixos 
temáticos e instrumentais oferecem, o ensino de filosofia se torna uma repetição mecânica dos textos filosóficos já estabelecidos pelo cânone. Uma vez que esses foram escritos em contextos tão distintos do cotidiano dos alunos, esses se sentiriam completamente desinteressados no conteúdo se não houvesse a devida apresentação didática dos dois primeiros eixos, tornando assim a aula de filosofia em uma memorização de teorias clássicas. Além disso, percebe-se uma grande prioridade dada aos textos clássicos nos documentos governamentais que normatizam o currículo de filosofia. As Orientações curriculares nacionais (OCNs), por exemplo, afirmam que o ensino de filosofia tem a finalidade de desenvolver certas capacidades críticas e argumentativas, mas essas somente podem ser efetivadas pelo contato com o texto canônico:

O que seria um olhar especificamente filosófico? Não basta dizer que é especificamente filosófico o olhar analítico, investigativo, questionador, reflexivo, que possa contribuir para uma compreensão mais profunda da produção textual específica que tem sob seu foco. Ora, nada impede que o cientista desenvolva um tal olhar. O fundamental aparece a seguir, conferindo a marca de conteúdo e de método filosófico: é imprescindível que ele tenha interiorizado um quadro mínimo de referências a partir da tradição filosófica (BRASIL, 2006, p. 31).

Desse modo, as OCNs consideram como traço específico da filosofia o fato que ela tem uma relação especial com o seu cânone. Na medida em que as capacidades críticas e argumentativas podem ser desenvolvidas por outras disciplinas, a filosofia o faria de modo especial por utilizar das teorias do seu passado como ferramentas para essa finalidade. Entretanto, quais são exatamente esses textos que conferem à filosofia esse lugar especial? As OCNs (2006) mencionam trinta conteúdos que poderiam ser tratados no ensino médio, nenhum dos quais apresenta outras formas de filosofia que não sejam eurocêntricas ou possuam autores de outras etnias. Além disso, percebe-se que muitos desses conteúdos pressupõem que o aluno já tenha certo domínio de leitura e interpretação de texto, o que é desenvolvido principalmente no ensino fundamental e com acompanhamento apropriado da família e dos professores. Uma vez que a maioria dos alunos advém de condições sociais que impossibilitam esse desenvolvimento, eles teriam muito mais dificuldade com filosofia que outros alunos de melhores condições econômicas, de modo que mais facilmente eles pensariam "filosofia não é para mim".

Tal consequência social da escolha curricular já é apontada por Bourdieu no seu artigo de 1966, intitulado A escola conservadora (1998). Nesse trabalho, o sociólogo analisa como o capital cultural dos alunos, em grande parte consequência da condição social das suas famílias, é o principal fator que determina a permanência deles na escola. Observou-se, por exemplo, que os estudantes mais ricos têm uma probabilidade 40 vezes maior de entrar em cursos superiores que os estudantes advindos das classes mais baixas (BOURDIEU, 1998, p. 43-44), uma vez que eles já tinham adquirido da sua família uma série de referências culturais que os auxiliaram no seu processo educativo. Frente a isso, os alunos de classe baixa e suas famílias interiorizam essas condições objetivas da impossibilidade de ascensão social e não 
veem motivos para continuar nesse processo, atribuindo esse fracasso às suas próprias aptidões intelectuais, uma vez que a relação entre a cultura escolar e dominante é dissimulada:

\begin{abstract}
O argumento central do sociólogo [de Bourdieu] é, então, o de que ao dissimular que sua cultura é a cultura das classes dominantes, a escola dissimula igualmente os efeitos que isso tem para o sucesso escolar das classes dominantes. As diferenças nos resultados escolares dos alunos tenderiam a ser vistas como diferenças de capacidades (dons desiguais) enquanto, na realidade, decorreriam da maior ou menor proximidade entre a cultura escolar e a cultura familiar do aluno (NOGUEIRA; NOGUEIRA, 2002, p. 30).
\end{abstract}

Desse modo, a inculcação da tradição filosófica europeia é um instrumento de reprodução da formação social, no qual as classes dominantes encontram um meio de manter a ordem social. Uma prova disso é o fato de que o capital cultural dos alunos de classe alta é muito mais valorizado do que o capital herdado pelos alunos de classes média e baixa. $O$ fato de que os alunos de classe alta têm em geral mais facilidade ao tratar de textos da tradição filosófica clássica faz com que a prioridade que o sistema de ensino brasileiro confere ao texto canônico de filosofia seja um instrumento de preservação da desigualdade social no nosso país.

A partir dessas reflexões sobre o sistema de ensino, bem como sobre como a matéria de filosofia se insere dentro desse sistema, torna-se necessária a pergunta: como é possível um modo de resistência a esse modelo? Para responder a isso, precisamos da distinção feita no início desse artigo, a saber, entre educação maior e a menor. O filósofo brasileiro Sílvio Gallo, no seu artigo Em torno de uma educação menor (2002), aborda essa temática a partir de uma classificação entre dois tipos de professores: o profeta, que, partindo das suas vivências materiais no âmbito escolar, apresentaria a possibilidade de uma mudança, e o militante, que tentaria realizar essas possibilidades. Desse modo, o professor militante perceberia as desigualdades culturais entre os seus alunos, bem como o fato de que o seu conteúdo de aula e a sua atuação no sistema de ensino ajudam a replicar essas discrepâncias, e tentaria construir, nesse mesmo contexto, as condições para sua mudança. Com isso, a sua atuação na escola seria pensada a partir da sua relação direta com os seus alunos e nas suas necessidades específicas, não mais sendo direcionado pelas diretrizes das OCNs; o professor deixaria de fazer uma educação maior para a realização de uma educação menor.

O conceito de educação menor foi criado por Gallo (2002) utilizando-se dos trabaIhos de Deleuze e Guattari (1986) sobre a literatura de Franz Kafka. Em Kafka: towards a minor literature, os pensadores franceses analisaram a obra do escritor tcheco segundo o ponto de vista da dicotomia entre literatura maior e a literatura menor. A primeira é caracterizada pela sua concordância com os princípios da tradição vigente, tomada como a literatura padrão, elitizada e pertencente ao capital cultural mais valorizado pelo sistema de ensino. Em contrapartida, a literatura menor se caracteriza por ser uma subversão da língua e estilo da literatura maior: no caso de Kafka, o seu alemão estava mais próximo da língua falada pelas classes populares de Praga do que dos poemas de 
Goethe, os seus escritos fazem uma denúncia da angústia e exclusão sofridas por todos os tchecos e judeus em um país ocupado por um povo estrangeiro, ao passo que a literatura maior daria mais foco aos dramas individuais e subjetivos dos seus personagens:

\begin{abstract}
As três características da literatura menor são a desterriorialização da linguagem, a conexão do individual com a imediação política e o conjunto da enunciação. Nós podemos dizer também que "menor" não mais designa literaturas específicas, mas as condições revolucionárias para cada literatura dentro do coração do que é chamado de literatura maior (ou estabelecida) (DELEUZE; GUATTARI, 1986, p. 18, tradução própria).
\end{abstract}

Todas essas características também se aplicam à educação. A possibilidade da educação menor somente ganha materialidade porque professor e aluno se encontram dentro do mesmo sistema de ensino, marcado pela educação maior. Nesse contexto, o sentimento de comunidade, tão essencial à literatura menor, faz com que o professor militante viva junto com os seus alunos as suas desigualdades sociais e culturais, para que, em conjunto com eles, ele possa criar condições de superá-las. Desse modo, a educação menor é essencialmente comunitária e política.

Outra característica comum à literatura e à educação menor é a desterriorialização de certas características da sua contraparte maior. No caso da literatura, essa desterriorialização ocorre principalmente na língua escrita, utilizando a linguagem estabelecida como uma forma de expressão das condições menores do autor e da sua comunidade. Quanto à educação menor, ela deve procurar subverter os mecanismos da educação maior para os seus próprios fins. Gallo, no seu artigo de 2002, caracteriza essa desterriorialização como uma simples resistência aos princípios da educação maior: não permitir que haja uma subjetivação dos alunos, ensinar-lhes aquilo que não se encontra nos parâmetros nacionais, entre outras formas de protesto. Enquanto que, de fato, esses modos de desterriorialização são próprios da educação menor, acredito que faltou a Gallo uma análise mais profunda do que seria a educação maior e quais seriam os seus dispositivos de controle, uma vez que o entendimento desses pode servir como fundamento para uma educação menor efetiva. Partindo das análises bourdieunianas expostas acima, considerarei nas próximas seções como pode existir uma educação menor de filosofia no atual contexto brasileiro.

\title{
A educação menor como possibilidade de resistência
}

Como foi visto acima no que diz respeito à educação maior, a autoridade escolar (AuE) é o mecanismo de legitimação que o sistema de ensino (SE) garante ao professor para que o seu discurso, denominado de "trabalho escolar" (TE), consiga ser considerado como objetivo e verdadeiro, dissimulando, desse modo, o arbitrário cultural que o fundamenta. No caso do ensino de filosofia no Brasil, o arbitrário cultural a ser perpetuado é o da homogeneidade da filosofia clássica, uma vez que não há na OCNs qualquer referência a filosofias feitas por outras culturas não europeias. 
Desse modo, torna-se imprescindível a criação de uma didática menor para evitarmos a reprodução dos arbitrários culturais previamente expostos. Para tanto, é necessário uma subversão desses princípios maiores para a realização do projeto menor de resistência a eles. Na atual perspectiva, um dos mecanismos passíveis de serem subvertidos são os próprios conteúdos de filosofia prescritos pela OCNs. Nesse caso, tratar-se-ia de uma utilização da filosofia clássica na sala de aula como ferramentas para entender o próprio contexto social dos alunos e do seu papel na vida cultural deles. Esse processo corresponde à etapa didática que Gallo (2006) denomina de "investigação":

Trata-se de buscar elementos que permitam a solução do problema. Uma investigação filosófica busca os conceitos na história da filosofia que podem servir como ferramentas para pensar o problema em questão. [...] Ela [história da filosofia] não é tomada como o centro do currículo, mas como um recurso necessário para pensar o nosso próprio tempo, nossos próprios problemas (GALLO, 2006, p. 28).

Além disso, pode também o professor nessa etapa trazer outras referências que não se encontrem dentro da filosofia clássica, mas que ofereçam um contraponto a ela. Por exemplo, em uma aula acerca do contratualismo de John Locke (1998), pode-se contrastar essa teoria com escritos de Djamila Ribeiro e Sueli Carneiro, filósofas brasileiras que, além de se encontrarem mais próximas do contexto social dos alunos que o liberalismo de Locke (1998), oferecem boas críticas a ele, as quais, com a ajuda do professor militante, auxiliariam os alunos a repensar a sua posição social:

[...] os conceitos podem ser armas de transformação ou armas de conservação, dependendo das intenções de quem os usa. A aula de filosofia como oficina de conceitos está longe, portanto, de ser um empreendimento ingênuo ou alienado. Pode ser uma arma de luta; o conceito pode ser ferramenta de engajamento (GALLO, 2006, p. 29).

Outro aspecto importante para a didática menor é o de valorização e ampliação do capital cultural dos alunos. Como foi exposto anteriormente, o principal mecanismo pelo qual a escola serve como ferramenta para a manutenção das desigualdades sociais é a supervalorização do capital cultural das classes altas e, por consequência disso, a desvalorização do capital cultural dos alunos de classe baixa, fazendo com que esses desistam da escola mais cedo e não tenham as mesmas oportunidades que os outros alunos. Para resistir a isso, o professor militante deve aproximar o arbitrário cultural a ser inculcado com o capital cultural dos seus alunos, o que envolve conhecê-los e se sensibilizar com as injustiças de que são vítimas. Na didática de Gallo (2006), essa valorização é mais adequada à etapa de sensibilização, na qual o professor procura trazer o tema da aula o mais próximo possível ao mundo dos seus alunos. Dentro de uma didática menor, isso deve ser feito partindo de uma apropriação do capital cultural dos alunos e de uma aproximação daquele com o conteúdo da aula e de 
outras formas de cultura. Uma música de rap, por exemplo, pode trazer tantas questões sobre justiça social quanto um romance de Jorge Amado ou um texto de John Rawls: basta apenas que o professor reconheça isso e se aproprie dessas três formas de tratar do mesmo assunto.

Há, ainda, mais uma característica da educação maior a ser subvertida para as finalidades da educação menor. Tal qual foi feito com as noções de arbitrário cultural e trabalho escolar, a autoridade escolar, característica determinante na relação entre professor e aluno na educação maior, deve ser repensada nos moldes comunitários da educação menor. Como veremos na próxima seção, isso exige uma dissolução da relação clássica entre professor e aluno.

\section{Sobre a relação entre professor(a) e aluno(a) na educação menor}

A autoridade escolar, entendida como a forma institucionalizada da autoridade pedagógica, é essencialmente uma função do sistema de ensino para a dissimulação do arbitrário cultural que fundamenta a aparente legitimidade e objetividade do trabalho escolar, de modo que a possibilidade da subversão desse mecanismo em prol de uma educação menor parece ser bastante pequena. Conforme apontam Bourdieu e Passeron (1982), uma autoridade pedagógica que revela os mecanismos de sua legitimidade perde a sua credibilidade com o seu público e, com isso, a possibilidade de sua ação. Assim, esses mecanismos devem permanecer escondidos para que continue a perpetuação do seu arbitrário cultural. Além disso, nessa perspectiva até mesmo o professor, principal detentor da autoridade escolar, é desconhecedor das condições objetivas de sua prática, uma vez que acredita que as suas práticas e juízos são classificadores neutros e objetivos de seus alunos. Analisando a relação das classificações usadas por um professor de filosofia para as capacidades dos seus alunos com a sua classe social, Bourdieu e Saint Martin(1998) ratificam:

É também porque acreditam pronunciar um julgamento estri-
tamente escolar que o julgamento social que se mascara sob
os considerandos eufemísticos de sua linguagem escolar (..)
pode produzir seu efeito próprio: fazendo crer aos que são
seu objeto que esse julgamento se aplica ao aluno [...], à sua
"pessoa" ou à sua "inteligência", e jamais, em todo caso, à sua
pessoa social [...] (BOURDIEU; SAINT-MARTIN, 1998, p. 199).

Desse modo, para perpetuar a ordem social e o arbitrário cultural que Ihe são as condições de possibilidade, a autoridade escolar é conferida ao professor para a inculcação do trabalho escolar e a classificação dos seus alunos, que se pressupõe neutra e objetiva.

Na medida em que o professor militante deve primeiro perceber a sua função dentro do sistema de ensino para depois criar as possibilidades de sua mudança, ele deve se perceber como um dos principais agentes da validação da ordem social que cria essa desigualdade cultural entre seus alunos e que fora levado a essa posição pela própria estrutura do sistema de ensino. É a partir dessa percepção que o sentimento de comunidade, característico da 
educação menor, surge como condição de possibilidade para uma resistência àqueles mecanismos. Uma vez que todo uso de autoridade escolar é uma maneira de legitimação do sistema de ensino, a única forma de se resistir a ele é pela renúncia da autoridade escolar, de modo que a caracterização clássica do professor como aquele que detém todos os conhecimentos, ao passo que a tarefa dos alunos é simplesmente os assimilar, deve ser abandonada.

Dado que as didáticas tradicionais pressupõem uma relação bem definida entre professor e alunos, como seria possível uma didática menor sem essa relação? Silvio Gallo (2006) nos aponta para essa direção quando trata da aula de filosofia como uma oficina de conceitos. Partindo dos estudos de Deleuze e Guatarri (1986), Gallo (2006) entende a atividade filosófica por excelência como a criação de novos conceitos, entendidos aqui como formas racionais de se entender e tentar responder os problemas vindos das experiências da vida do filósofo. Desse modo, a aula de filosofia deve ser entendida como um lugar propício aos alunos fazerem essa atividade conceitual criativa; por consequência disso, a tarefa do professor deve ser orientá-los nessa empreitada. Ele ainda terá mais domínio conceitual que a maioria dos alunos por conta de toda a sua formação anterior, mas isso deve ser usado com a finalidade de promover nos alunos a atividade do pensamento, bem como para instigar uma crítica à tradição filosófica do arbitrário cultural. Portanto, não se trata de abandonar a história da filosofia como um conteúdo a ser transmitido, mas que o foco da aula deve passar dela para outras filosofias e para a atividade de criação de conceitos dos alunos, sempre com a orientação do professor.

\section{Considerações finais}

No presente artigo, pretendeu-se analisar o modo como a instituição escolar se insere no contexto macrossociológico, bem como o papel do ensino de filosofia dentro desse. Para tanto, foram utilizadas os estudos de Pierre Bourdieu (1982; 1998) sobre a função da escola como um mecanismo de reprodução do arbitrário cultural imposto pelas classes dominantes a fim de manter a atual ordem social. A partir disso, contatou-se que o ensino de filosofia no Brasil serve essa mesma função, tendo como base principalmente as OCNs, nas quais a filosofia serve para a manutenção de valorização de autores brancos e europeus. Com isso, foi considerada a possibilidade de uma educação menor, apresentada inicialmente nos escritos de Sílvio Gallo (2002; 2006), cuja principal função seria a subversão dos mecanismos e valores da educação maior a fim de denunciá-la e questioná-la. Dessa consideração, foram apontadas algumas estratégias didáticas de filosofia que serviriam aos propósitos da educação menor: a utilização dos textos clássicos como ferramentas para entender o cotidiano dos alunos; a apresentação de textos não canônicos que façam críticas ao modo estabelecido de se fazer filosofia; a valorização do capital cultural herdado pelos alunos dos seus contextos sociais; e pela dissolução da relação clássica entre professor e alunos, o que é possível mediante a realização de aulas não expositivas, nas quais professor e aluno criariam juntos conceitos e argumentos para resolver o problema filosófico que compõe o tema da aula. 


\section{REFERÊNCIAS}

BOURDIEU, Pierre; PASSERON, Jean-Claude. A Reprodução: Elementos para uma teoria do sistema de ensino. Rio de Janeiro: Francisco Alves Editora, 1982.

BOURDIEU, Pierre. A escola conservadora: desigualdades frente à escola e à cultura. In: NOGUEIRA, Maria Alice; CATANI, Afrânio. (Orgs.). Escritos de Educação. Petrópolis: Editora Vozes, 1998, p. $39-64$.

BOURDIEU, Pierre; SAINT-MARIN, Monique de. As categorias do juízo professoral. In: NOGUEIRA, Maria Alice; CATANI, Afrânio. (Orgs.). Escritos de Educação. Petrópolis: Editora Vozes, 1998, p. $185-216$.

BRASIL. Ministério da Educação. Secretaria de Educação Básica. Orientações Curriculares Nacionais para o Ensino Médio. v. 3. Ciências Humanas e suas tecnologias. Brasília, DF, 2006.

DELEUZE, Gilles; GUATARRI, Félix. Kafka: toward a minor literature. Minneapolis: University of Minnesota Press, 1986.

GALLO, Sílvio. A Filosofia e seu ensino: conceito e transversalidade. Ethica, v. 13, n. 1, 2006, p. $17-35$.

GALLO, Sílvio. Em torno de uma educação menor. Educação e Realidade, v. 27, n. 2, 2002, p. $169-178$.

HEY, Ana Paula; et al. A Sociologia da educação de Bourdieu na revista Actes de la Recherche en Sciences Sociales. Tempo Social, revista de sociologia da USP, v. 30, n. 2, 2018, p. $171-195$.

LOCKE, John. Dois tratados sobre o governo. São Paulo: Martins Fontes, 1998.

NOGUEIRA, Cláudio Marques Martins; NOGUEIRA, Maria Alice. A Sociologia da Educação de Pierre Bourdieu: limites e contribuições. Educação \& Sociedade, v. 23, n. 78, 2002, p. $15-36$.

ROCHA, Ronai Pires da. A didática na disciplina de filosofia. In: CARVALHO, Marcelo; CORNELLI, Gabriele (Orgs.). Ensinar Filosofia. v. 2, Santa Maria: Editora Curso Caxias, 2013, p. $39-47$.

\section{Correspondência}

Matheus Diesel Werberich - Rua dos Andradas, 550, apto 301, bairro Centro, CEP: $97010-$ 030, Santa Maria, Rio Grande do Sul, Brasil.

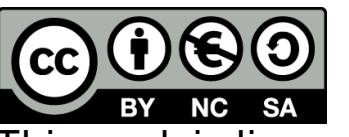

This work is licensed under a Creative Commons Attribution-NonCommercial 4.0 International (CC BY-NC 4.0) 